Neuroepidemiology 2011;36:192-193

DOI: $\underline{10.1159 / 000328276}$

\section{Physical Activity in Multiple Sclerosis: The Missing Prescription}

\section{Julián Benito-León}

Department of Neurology, University Hospital '12 de Octubre', Centro de Investigación Biomédica en Red sobre Enfermedades Neurodegenerativas, and Department of Medicine, Faculty of Medicine, Complutense University, Madrid, Spain

Multiple sclerosis (MS) is one of the most common chronic disabling neurologic diseases in young adults, affecting approximately 1 in 1,000 persons $[1,2]$. Although none of the current hypotheses on the etiology of MS is particularly convincing, there is an increasing body of evidence that suggests that this disease is mediated by an autoimmune reaction to a widespread pathogen $[3,4]$, ubiquitous in the developed world, often affecting susceptible people before the age of 15 years [5].

The plethora of symptoms involving multiple systems as well as side effects from medications mean that health-related quality of life (HRQOL) is often poor in individuals with MS and their families [6-15]. Hence, it is imperative to focus research efforts to search for interventions which offer to improve HRQOL in individuals with MS. One promising area is physical activity, which has been associated with improvements in HRQOL of life in individuals with MS [16].

At baseline, MS sufferers are more likely to be sedentary and inactive compared with the general population [17]. Research over the past several decades confirms the health benefits of regular physical activity, including improved cardiovascular function and HRQOL, with reduced risks of morbidity and mortality from cardiovascular heart disease [18]. However, although there is evidence of a linear inverse association between physical activity and cardiovascular comorbidities in the general population [19], this has not yet been established in individuals with MS. Motl et al. [20] provide us with the first serious attempt to examine this question. The authors recruited 561 individuals with MS who completed demographic, cardiovascular comorbidities, disability status, and physical activity self-report assessments, and then wore an accelerometer for 7 days [20]. Linear regression indicated that both self-reported physical activity and objectively measured physical activity were associated with the number of self-reported cardiovascular comorbidities, independent of disability status and other possible confounding variables, including age.

The study had several strengths, including the well thoughtout approach to the statistical analyses but the study was not with- out limitations. The main limitation is that the cross-sectional design does not establish the temporal sequence between physical activity and self-reported cardiovascular comorbidities, and the observed association could reflect pre-existing conditions and/or an effect of physical activity on cardiovascular comorbidities or cardiovascular comorbidities on physical activity. Indeed the investigators noted that future studies should be prospective longitudinal examinations of physical activity and cases of cardiovascular disease as well as laboratory-based examinations of the association between physical activity and subclinical atherosclerosis, even in the absence of overt cardiovascular symptoms. Nevertheless, even after accounting for the study limitations, the authors appear to demonstrate that physical activity is inversely and independently associated with self-reported cardiovascular comorbidities in individuals with MS in line with the general population.

Shortly after MS is diagnosed, astute clinicians begin educating the patient with an in-depth discussion about current symptoms and future symptoms that might emerge later. It appears likely that in the near future, promotion of physical activity may become part of the clinical armamentarium of any practicing clinician who treats individuals with MS. If indeed those with MS are at increased risk of developing cardiovascular events, it is incumbent on us to work in a multidisciplinary fashion to establish a suitable therapeutic approach. The research by Motl and colleagues [20] should encourage more research on how physical activity may be of benefit in individuals with MS.

\section{Disclosure Statement}

Dr. Benito-León is supported by NIH R01 NS039422 from the National Institutes of Health, Bethesda, Md., USA.

\section{References}

1 Benito-León J, Martin E, Vela L, Villar ME, Felgueroso B, Marrero C, Guerrero A, Ruiz-Galiana J: Multiple sclerosis in Móstoles, central Spain. Acta Neurol Scand 1998;98:238-242.

-2 Pugliatti M, Sotgiu S, Rosati G: The worldwide prevalence of multiple sclerosis. Clin Neurol Neurosurg 2002;104:182-191.

-3 Kakalacheva K, Comabella M: Epstein-Barr virus and multiple sclerosis: causation or association? Future Microbiol 2010;5:1617-1619.

-4 Benito-León J, Pisa D, Alonso R, Calleja P, Díaz-Sánchez M, Carrasco L: Association between multiple sclerosis and Candida species: evidence from a case-control study. Eur J Clin Microbiol Infect Dis 2010; 29:1139-1145.

5 Benito-León J, Bermejo-Pareja F: Is the epidemiology of multiple sclerosis changing? Rev Neurol 2010;51:385-386.

6 Benito-León J, Morales JM, Rivera-Navarro J: Health-related quality of life and its relationship to cognitive and emotional functioning in multiple sclerosis patients. Eur J Neurol 2002;9:497-502.

$\checkmark 7$ Benito-León J, Martínez-Martín P: Health-related quality of life in multiple sclerosis. Neurologia 2003;18:210-217.

\section{KARGER}

두 2011 S. Karger AG, Basel

Fax +41613061234 E-Mail karger@karger.ch www.karger.com 
8 Benito-León J, Morales JM, Rivera-Navarro J, Mitchell A: A review about the impact of multiple sclerosis on health-related quality of life. Disabil Rehabil 2003;25:1291-1303.

-9 Morales-Gonzáles JM, Benito-León J, Rivera-Navarro J, Mitchell AJ, GEDMA Study Group: A systematic approach to analyse health-related quality of life in multiple sclerosis: the GEDMA study. Mult Scler 2004; $10: 47-54$

10 Mitchell AJ, Benito-León J, González JM, Rivera-Navarro J: Quality of life and its assessment in multiple sclerosis: integrating physical and psychological components of wellbeing. Lancet Neurol 2005;4:556566.

11 Rivera-Navarro J, Morales JM, Benito-León J: Informal caregiving in multiple sclerosis patients: data from the Madrid demyelinating disease group study. Disabil Rehabil 2003;25:1057-1064.

-12 Rivera-Navarro J, Morales-González JM, Benito-León J, Mitchell AJ: The social and familial dimensions: experiences of caregivers and people with multiple sclerosis: the Gedma Study. Rev Neurol 2008;47:281285.

13 Rivera-Navarro J, Benito-León J, Oreja-Guevara C, Pardo J, Dib WB, Orts E, Belló M; Caregiver Quality of Life in Multiple Sclerosis (CAREQOL-MS) Study Group: burden and health-related quality of life of Spanish caregivers of persons with multiple sclerosis. Mult Scler 2009; 15:1347-1355.

14 Benito-León J, Rivera-Navarro J, Guerrero AL, de Las Heras V, Balseiro J, Rodríguez E, Belló M, Martínez-Martín P, Caregiver Quality of Life in Multiple Sclerosis (CAREQOL-MS) Study Group: The CAREQOLMS was a useful instrument to measure caregiver quality of life in multiple sclerosis. J Clin Epidemiol 2011;64:675-686.
15 Rivera-Navarro J, Benito-León J: The social dimension of the quality of life in multiple sclerosis. Rev Neurol 2011;52:127.

16 Motl RW, Gosney JL: Effect of exercise training on quality of life in multiple sclerosis: a meta-analysis. Mult Scler 2008;14:129-135.

17 Motl RW, McAuley E, Snook EM: Physical activity and multiple sclerosis: a meta-analysis. Mult Scler 2005;11:459-463.

18 Francis K: Physical activity in the prevention of cardiovascular disease. Phys Ther 1996;76:456-468.

19 Williams PT: Physical fitness and activity as separate heart disease risk factors: a meta-analysis. Med Sci Sports Exerc 2001;33:754-761.

20 Motl RW, Fernhall B, McAuley E, Cutter E: Physical activity and selfreported cardiovascular comorbidities in persons with multiple sclerosis: evidence from a cross-sectional analysis. Neuroepidemiology 2011;36:183-191.

Dr. Julián Benito-León

Department of Neurology, University Hospital '12 de Octubre'

Av. de Córdoba, s/n

ES-28041 Madrid (Spain)

Tel.+34913908 600,E-Mail jbenitol@meditex.es 